\title{
A ORDEM DO SUJEITO EM CONSTRUÇÕES MONOARGUMENTAIS: CONFIRMANDO DIAGNÓSTICOS
}

\author{
ORDER OF SUBJECT IN VERBS CONSTRUCTIONS WITH ONE ARGUMENT: \\ CONFIRMING DIAGNOSIS
}

Fabrícia Silva

Mestranda em Linguística pelo Programa de Pós-graduação em Linguística da Universidade Federal de Santa Catarina/CAPES fabriciasylva@hotmail.com

Fernanda Lima Jardim Miara Doutoranda em Linguística pelo Programa de Pós-graduação em Linguística da Universidade

Federal de Santa Catarina/CNPq nandalj.miara@hotmail.com

\begin{abstract}
RESUMO: A ordem do sujeito no português do Brasil - doravante PB - está diretamente vinculada à transitividade verbal, uma vez que a questão da posposição do sujeito ao verbo se mostra associada a restrições sintático-semânticas e, principalmente, ao tipo de verbo em questão: o monoargumental. Muitos estudos, dos quais podemos citar Berlinck (1989) e Coelho $(1999,2000,2006)$, já mostraram que construções com verbos monoargumentais no PB, em especial os inacusativos existenciais, são um dos fatores favoráveis à ocorrência da ordem verbo-sujeito (VS). Esta pesquisa tem como objetivo observar, por meio de um estudo quantitativo, quais condicionadores - linguísticos e/ou extralinguísticos - favorecem a ordem VS em sentenças, sob uma perspectiva variacionista da língua (cf. LABOV, 2008 [1972]), somada ao gerativismo. O corpus deste trabalho é composto por oito entrevistas do Núcleo de Pesquisa VARSUL (Variação Linguística na Região Sul do Brasil), de informantes de dois bairros não urbanos da cidade de Florianópolis - SC. Os resultados aqui apresentados corroboram outros estudos: a ordem VS constitui-se, na maioria dos casos, de verbos inacusativos existenciais, sem marca de concordância, sendo formada por sujeitos do tipo SN, que tanto podem ser agente ou tema, aceitando traços [ \pm animados].
\end{abstract}

PALABRAS-CHAVE: Verbos monoargumentais. Ordem do sujeito. Inacusativos.

ABSTRACT: The order of the subject in Portuguese of Brazil - now BP - is directly linked to verbal transitivity, since the question of the postposition of the subject to the verb shows associated with syntactic-semantic constraints, and especially the type of verb in question: monoargumental. Many studies, of which we mention Berlinck (1989) and Coelho (1999, 2000, 2006), have shown that buildings with only one argument verbs in BP, especially the existential unaccusative, are one of the factors leading to the occurrence of verb-subject (VS). This research aims to observe, by means of a quantitative study which conditioners linguistic and/or extralinguistic - favor the VS order in sentences, under a variationist perspective of language (cf. Labov 2008 [1972]), plus to the generative approach. The corpus of this study consists of eight interviews of the Research Center VARSUL, of two informants not urban neighborhoods in Florianópolis - SC. The results presented here corroborate other studies: the VS order appears to, in most cases, existential unaccusative verbs without agreement marks, being formed by citizens of the SN type, which can be either agent or theme, accepting traits [ \pm animated]. 
KEYWORDS: Only one argument verbs. Order of the subject. Unaccusative.

\section{INTRODUÇÃO}

A ordem do sujeito no português é um fenômeno linguístico que sofreu alterações em sua estrutura ao longo dos séculos. Muitos estudos mostram que tanto a ordem sujeito-verbo (SV) como a ordem verbo-sujeito (VS) eram usadas naturalmente nos séculos XVIII e XIX, sendo uma questão opcional e até mesmo subjetiva de uso (BARBOSA, 1830), mas que, gradativamente, a ordem VS foi se transformando numa construção cada vez mais enrijecida, restrita a contextos especiais, de forma que a ordem SV tonou-se, na maioria dos casos, predominante (PONTES, 1987).

Berlinck (1989), em seu estudo sobre a ordem do sujeito, mostra, com base em uma análise diacrônica, composta por cartas de cunho pessoal dos séculos XVIII e XIX, e em uma análise sincrônica, formada por gravações orais de jovens universitários entre vinte e trinta anos do século XX, que a ordem SV ganha um aumento no uso, à medida que a construção VS se limita a contextos específicos, visto que há um decréscimo da ordem VS, que percorre índices de 42\%, 31\% e 21\% no decorrer dos anos 1750, 1850 e 1987, respectivamente.

De acordo com os resultados de Berlinck (1989), para sua amostra sincrônica, o tipo de verbo predicador é um dos importantes condicionadores da ordem VS, sendo que se trata de um fator de natureza formal, pois, conforme afirma a autora, "os resultados gerais mostram que o encaminhamento da diminuição de freqüência de V SN atingiu antes e com mais intensidade os contextos "mais transitivos"' (BERLINCK, 1989, p. 101). Sabe-se que, nos três séculos estudados, o tipo de verbo sempre se mostrou um fator forte para explicar a mudança, sendo que os inacusativos existenciais apresentam a inversão VS quase que categoricamente para os séculos XVIII (100\%), XIX (97\%) e XX (99\%). Afirma também a autora que o único grupo de fatores que apresenta o mesmo grau de relevância para os três séculos em questão é a forma de realização do $S N$, não sendo, portanto, um condicionador que distingue as diferenças entre os anos analisados.

Um dos objetivos de Berlinck (1989) é traçar o percurso de transição da ordem do sujeito no PB, apoiada na Teoria da Variação e Mudança Linguística, a fim de poder compreender os princípios que regem a variação e a mudança. Segundo ela, a ordem enrijecida sujeito-verbo-objeto (SVO) se estabeleceu diante da necessidade de se evitar contextos ambíguos, por conta do apagamento do objeto direto anafórico, que se deu também entre os séculos XVIII e XX, dentre outros fatores, havendo, portanto, um encaixamento na estrutura sintática do $\mathrm{PB}$, reorganizando-o.

[...] o grau de probabilidade de ocorrência de V SN com um dado verbo está associado ao grau de possível ambigüidade dessa construção numa relação inversamente proporcional: quanto maior é a chance de o SN ser interpretado com uma função que não a de argumento externo (principal) de $\mathrm{V}$, menor é a probabilidade de que ele ocorra em V SN, e vice-versa. Por uma decorrência natural, desse princípio, verbo-predicadores com mais de um argumento são sempre os mais avessos a V SN, porque existe, nesses casos, a possibilidade de que um SN posposto ao qual se deveria atribuir função-sujeito seja percebido como objeto. É claro que essa possibilidade varia de acordo com as relações específicas entre cada predicador e seus argumentos. De um modo geral, porém, o posicionamento dos constituintes é tomado como uma das características indicativas de sua função sintática nesse tipo de construção; talvez como a principal delas. (BERLINCK, 1989, p. 104-105). 
Sabe-se que descrever a "língua como objeto homogêneo [...] é em si mesmo desnecessariamente irrealista e representa um retrocesso em relação às teorias estruturais, capazes de acomodar os fatos da heterogeneidade ordenada" (WEINREICH; LABOV; HERZOG, 2006 [1968], p. 35). Muitos linguistas, aos poucos, foram se convencendo de que a ideia de um idioleto homogeneamente estruturado não caberia mais à teoria da mudança linguística, de tal forma que foram admitindo que a variabilidade e a sistematicidade não se excluem. Pode-se pensar, dessa forma, que a ordem livre do sujeito no PB passou por transformações, de maneira que em certos casos houve enrijecimento da estrutura, sendo liberada apenas uma ou outra ordem - SVO ou VS - para determinados tipos verbais.

Nosso objetivo é, por meio de uma pesquisa quantitativa, analisar a ordem do sujeito em construções monoargumentais de sentenças do PB, extraídas de amostras de fala do Núcleo de pesquisa VARSUL, especificamente de zonas não urbanas de Florianópolis - SC, buscando conhecer quais fatores linguísticos e extralinguísticos favorecem a ordem VS. Para tanto, este estudo está organizado da seguinte maneira: na primeira seção, foram elencados alguns trabalhos a respeito da ordem do sujeito, bem como pesquisas sobre verbos monoargumentais; à segunda seção está reservada a metodologia adotada, além das hipóteses levantadas; na terceira seção, os resultados deste estudo serão analisados e descritos; e, por fim, serão apresentadas as considerações finais, seguidas das referências.

\section{VERBOS MONOARGUMENTAIS: CONFIRMANDO DIAGNÓSTICOS}

São chamados de verbos monoargumentais aqueles verbos que apresentam apenas um argumento, sendo que este pode ser interno ou externo. Estes são chamados de inergativos ou intransitivos e aqueles de inacusativos. De acordo com a gramática gerativa, esses dois verbos têm estruturas diferentes, conforme a representação em (1) e (2), pois, enquanto os inergativos apresentam um argumento que é gerado à esquerda do verbo, na estrutura profunda, o argumento de um inacusativo é gerado à direita do verbo.

(1) Verbo intransitivo ou inergativo

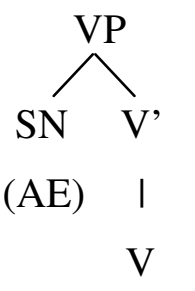

(2) Verbo inacusativo

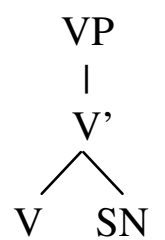

(AI)

A questão da monoargumentalidade é tratada por Ciríaco e Cançado (2004), que mostram, empiricamente, o comportamento sintático-semântico de verbos monoargumentais no PB. De acordo com elas, as diferenças entre verbos inergativos e inacusativos não podem ser explicadas apenas com base em suas diferenças sintáticas, pois a distinção também é semanticamente determinada. Como mostram as autoras - baseadas em estudos de Permulter (1978, 1980), Levin (1983), Marantz (1984), Rosen (1984), dentre outros -, enquanto os 
verbos inergativos apresentam argumentos com papéis temáticos agentivos, isto é, de sujeito prototípico, os inacusativos apresentam argumentos com características de temas, mais próximos de objetos diretos, havendo, pois, uma relação semântica entre eles. O objetivo maior do trabalho é mostrar que não há uma representação exata ou perfeitamente definida que delimite quais verbos são inacusativos ou inergativos, mas que existem muitos verbos que, em determinadas propriedades, se aproximam mais destes verbos do que daqueles e viceversa, enquanto outros se apresentam prototipicamente como inacusativos ${ }^{1}$ ou inergativos.

Conforme apontam as autoras, a literatura tem mostrado que verbos inacusativos apresentam propriedades com relação ao papel temático e à posposição, propriedades essas que, segundo elas, se mostram bastante frágeis em alguns aspectos como, por exemplo, pode ser observado em João amadureceu com a morte da mãe, visto que nessa sentença o verbo monoargumental amadurecer, embora se apresente como tema ou paciente, aproximando-se de verbos inacusativos, não aceita tão naturalmente a ordem VS, propriedade que, ao mesmo tempo, o afasta dessa mesma classe de verbos. Essa fragilidade também é reforçada por Ciríaco e Cançado (2004) por meio das sentenças Saiu a folha de pagamento e Sentou uma mulher legal do meu lado, uma vez que os verbos sair e sentar são geralmente verbos que apresentam sujeitos agentivos, uma característica de verbos inergativos, porém aceitam naturalmente a posposição, uma característica de verbos inacusativos. Com base nesses e em outros exemplos, as autoras propõem uma classificação mais flexível no que diz respeito à distinção dessas duas classes de verbos, admitindo a possibilidade de determinados verbos apresentarem tanto propriedades de verbos inergativos como de inacusativos, ao que chamam de verbos com comportamento misto.

Ciríaco e Cançado (2004) apresentam, em seu estudo, uma análise de 40 verbos monoargumentais que são observados sobre dois critérios semânticos e três sintáticos. Segundo as autoras, são considerados diagnósticos de inacusatividade a relação entre o tipo semântico de papel temático, já que verbos inacusativos têm a propriedade de apresentar um sujeito como tema, e a relação entre inacusatividade e o aspecto achievement, pois verbos inacusativos apenas expressam a perspectiva final do evento, sem mostrar o ponto em que o processo se inicia. No que se refere aos testes sintáticos aplicados, as autoras controlaram a posição do sujeito, a indeterminação do sujeito e a existência da forma de particípio, uma vez que, de acordo com elas, espera-se que verbos inacusativos apresentem a ordem posposta VS, que sejam determinados e que tenham a forma de particípio.

Dentre os grupos de fatores controlados pelas autoras, damos destaque para a posposição do sujeito, já que se tem apresentado como uma propriedade que muito contribui para distinguir verbos monoargumentais. Muitos estudos têm mostrado que verbos inacusativos aceitam mais facilmente a ordem VS, enquanto inergativos preferem a ordem $\mathrm{SV}$, na maioria das sentenças. Isso quer dizer que a posposição é mais naturalmente aceita em sentenças $^{2}$ do tipo Adoeceu uma criança na escola e Nasceu um bebê lindo hoje na maternidade, se comparadas a exemplos como Caminhou uma menina no salão e Andou uma criança por aqui. Assim, embora essas duas últimas sentenças, construídas com verbos de argumento externo, não sejam agramaticais, talvez soassem mais naturalmente na ordem SV, ordem contrária da que foi recém-apresentada. Porém, como destacam Ciríaco e Cançado (2004), o verbo sair, nesse caso, não apresenta nenhuma restrição, uma vez que a sentença Saiu um menino lá da sala permanece bastante natural na ordem posposta, o que sugere um comportamento particular de cada verbo com relação ao critério em questão.

\footnotetext{
1 As autoras afirmam que os diagnósticos de inacusatividade expostos em seu trabalho não são válidos necessariamente para todas as línguas.

${ }^{2}$ Exemplos retirados de Ciríaco e Cançado (2004).
} 
Enfim, Ciríaco e Cançado (2004) assumem que os verbos monoargumentais podem apresentar todas as características de inacusatividade, ao que chamam de inacusativos prototípicos, ou podem apresentar todas as características de inergatividade, ao que nomeiam inergativos prototípicos, ou ainda que podem se comportar como verbos de propriedades mistas - inacusativas/inergativas -, os chamados inacusativos ou inergativos menos prototípicos.

Em seu estudo sobre posposição do sujeito, Zilles (2000), além de controlar os grupos de fatores (i) tipo de verbo - transitivo, intransitivo e de ligação -, (ii) animacidade do sujeito - animado e inanimado -, (iii) forma de expressão do $S N$ - SN pleno e pronome -, (iv) idade e (v) escolaridade do informante, dentre outras variáveis, também controlou a (vi) localidade do informante, já que sua pesquisa tinha como foco a análise da fala ${ }^{3}$ de quatro cidades do Rio Grande do Sul com diferentes características e influências, a saber, Porto Alegre (capital), São Borja (fronteira com a Argentina: contato com espanhol), Flores da Cunha (colonização italiana: bilinguismo) e Panambi (colonização alemã: bilinguismo). ${ }^{4}$

Os resultados de Zilles (2000) mostraram que a ordem VS está diretamente associada a sentenças que apresentam: (i) sujeitos pronominais, especialmente os indefinidos e, em segundo lugar, os SNs plenos; (ii) verbos intransitivos e de ligação e (iii) sujeitos inanimados - dentre outros diagnósticos. Quanto aos grupos de fatores sociais, a autora justifica a não significância pelo fato de a mudança sintática VS $\rightarrow \mathrm{SV}$ já ter se completado, restando à ordem VS casos especiais e delimitados, uma vez que, "quando o uso de uma forma alcança percentuais de $95 \%$ ou mais, não parece possível identificar grandes diferenças" (ZILLES, 2000 , p. 80) para variáveis dessa natureza. Sendo assim, além da idade e a escolaridade, a localidade também não se mostrou relevante, já que Porto Alegre e São Borja apresentaram percentuais de $95 \%$ e Flores da Cunha e Panambi apresentaram percentuais de 93\%, para ordem SV, evidenciando um enrijecimento sintático, em grande medida, "o que pode ser interpretado como o estágio final de um processo de mudança na língua" (ZILLES, 2000, p. 92). Enfim, para as quatro cidades pesquisadas pela autora, as variáveis mais significativas para indicar favorecimento à posposição do sujeito foram as mesmas, a saber, tipo de SN, tipo de verbo e animacidade do sujeito, nessa ordem, apontando que o fenômeno da posposição está correlacionado a variáveis linguísticas e, mais que isso, que as amostras apontam "na direção de um mesmo sistema sintático" (ZILLES, 2000, p. 92).

A busca por um estatuto que definisse as características de construções com verbos monoargumentais também foi estudada por Coelho (2000) e Coelho et al.. (2006), combinando a abordagem sociolinguística quantitativa de Labov com a análise teórica abstrata de Chomsky, sob o modelo de Princípios e Parâmetros. Em sua pesquisa, Coelho (2000) elencou algumas variáveis linguísticas que julgou condicionadoras da ordem do sujeito das sentenças construídas com verbos monoargumentais. São elas: (i) natureza transitiva do verbo monoargumental; (ii) traços de definitude e de especificidade do SN; (iii) forma de realização do $S N$; (iii) estatuto [+/- pesado] do $S N$; e (iv) animacidade do $S N$. Porém, neste trabalho serão destacadas apenas as variáveis (i) e (iv), uma vez que mostraram resultados mais relevantes no controle da posposição do sujeito.

Sobre a variável (i), Coelho (2000) distingue verbos inacusativos existenciais, verbos inacusativos não existenciais e verbos intransitivos (ou inergativos). O propósito de controlar essa variável está em comprovar empiricamente se a legitimação da ordem VS é favorecida

\footnotetext{
${ }^{3}$ A amostra oral, referente às quatro cidades pesquisadas pela autora - Porto Alegre, São Borja, Flores da Cunha e Panambi -, estão incluídas no banco de dados do Núcleo de pesquisa VARSUL.

${ }^{4}$ Em seu estudo, Zilles (2000) inclui no corpus de análise orações ter/haver com sentido existencial, justificando que, nesses casos, o SN não é considerado sujeito.
} 
pelo tipo de verbo em questão, já que se espera que verbos inacusativos licenciem mais naturalmente a posposição do sujeito. De acordo com os resultados de Coelho (2000) e de Coelho et al. (2006), a hipótese foi atestada, pois existe uma correlação notável "[...] entre ordem dos constituintes e a variável natureza do verbo: há uma associação entre as construções intransitivas e a ordem SV; inversamente, a ordem VS se restringe a contextos monoargumentais de construções inacusativas, em especial, [...] existenciais" (COELHO et al., 2006, np). Em percentuais, Coelho et al. (2006) afirmam que, quanto à ordem do sujeito, 95\% dos verbos inacusativos existenciais apresentaram inversão na ordem, ao passo que os verbos inacusativos não existenciais mostraram $22 \%$ de inversão, contra $3 \%$ do verbos intransitivos (ou inergativos).

Com relação à variável (iv), constatou-se que há uma ligação entre argumentos [animados] e verbos inacusativos, embora estes também admitam argumentos [+animados]. Por outro lado, sabe-se que verbos inergativos apenas admitem sujeitos agentivos, ou seja, somente aceitam argumentos $[+ \text { animados] }]^{5}$, variável que remete à grade temática do verbo, também comentada por Ciríaco e Cançado (2004). Os resultados de Coelho (2000) para esta variável mostraram que $73 \%$ das sentenças de ordem VS apresentam seu argumento com o traço [-animado].

Coelho (2000) também faz um cruzamento entre as duas variáveis controladas em destaque - natureza do verbo e animacidade do SN - e observa que para o tipo de verbo inacusativo existencial, independentemente de o traço do SN ser [ \pm animando], maior é a frequência e a probabilidade de aparecer a ordem VS, atingindo 95\% dos casos, percentual que diminui para $59 \%$ e $18 \%$, em relação a verbos inacusativos não existenciais e intransitivos (ou inergativos), respectivamente, quando o traço do SN é [-animado]. Tais resultados evidenciam, assim, que a ordem VS pode ser considerada um dos diagnósticos de verbos inacusativos.

A variação da concordância verbal de terceira pessoa do plural, como mostra Monguilhott (2001), por exemplo, também é condicionada pela ordem do sujeito, pelo traço humano do sujeito e pelo tipo de verbo. Conforme a autora, verbos inacusativos têm maior probabilidade de não concordância, com percentual de $71 \%$, contra $82 \%$ de marca de concordância para verbos intransitivos (ou inergativos). A animacidade do sujeito, como já foi conferida em outros trabalhos aqui citados, também revela uma particularidade de verbos inacusativos, pois, segundo os resultados de Monguilhott (2001), há concordância em apenas $58 \%$ dos dados analisados quando o traço do sujeito é [-humano] e de $84 \%$, quando o traço é [+humano]. E quanto à posposição do sujeito, a pesquisa desta autora mostra que a ordem VS apresentou $52 \%$ de marca de concordância contra $84 \%$ para o sujeito anteposto ao verbo. Esses resultados revelam que há menor frequência e probabilidade de concordância verbal de terceira pessoa do plural, portanto, quando o verbo é inacusativo, a ordem em questão é a posposição VS e, finalmente, quando o sujeito apresenta traço [-humano].

Monguilhott (2001) também faz um cruzamento entre os fatores ordem do sujeito e traço humano, e, segundo os resultados, há uma constatação de hierarquia entre eles: embora o traço [-humano] não favoreça a frequência e a probabilidade de concordância, a posposição do sujeito é que rege, em maior grau, a não concordância para esses dois fatores, uma vez que verbos inacusativos, como já foi ressaltado, apresentam argumentos tanto com traço [+humano] quanto com traço [-humano], ao contrário de verbos intransitivos (ou inergativos), que apenas aceitam traço [+humano]. Diante disso, observa-se que a não concordância verbal também contribui para diagnosticar a inacusatividade.

\footnotetext{
${ }^{5}$ De acordo com Coelho (1999, p. 90), os casos em que aparecem SNs com o traço [-animando] restringem-se a sujeitos metonímicos como, por exemplo, "Aí o Instituto de Educação desfilava em peso" (FLP24L760).
} 


\section{METODOLOGIA}

“A língua é uma forma de comportamento social” ( LABOV, 2008 [1972], p. 215) e por isso precisa ser estudada em meio às comunidades, em meio à sociedade. Diante disso, a busca por dados linguísticos nas comunidades não deve se limitar a uma busca, na qual iremos encontrar apenas o fenômeno linguístico que se deseja. Mais que isso, a comunidade irá nos informar sobre o contexto socioeconômico da região, bem como sobre as relações sociais entre os falantes e os interlocutores, entre o ambiente e as pessoas, informações essas que poderão complementar nossos dados, sendo de grande importância para o estudo das línguas, pois, segundo Labov (2008 [1972]), todo o instante nossa linguagem informa o ouvinte sobre quem somos, o que fazemos, e responde ao interlocutor o que achamos dele. Dessa maneira, nossa linguagem nos identifica e se adequa às mais diversas situações do cotidiano.

"Para lidar com a língua, temos de olhar para os dados da fala cotidiana o mais perto e diretamente possível, [...] corrigindo e adequando a teoria para que ela se ajuste ao objeto visado" (LABOV, 2008 [1972], p. 236), uma vez que é na fala do dia-a-dia que observamos de fato o vernáculo dos falantes, isto é, a fala que recebe um menor grau de atenção justamente por ser menos monitorada. Segundo Labov (2008 [1972]), a pesquisa sociolinguística deve basear-se na coleta de dados de fala, feita por meio de entrevistas individuais gravadas. $\mathrm{O}$ objetivo dessas gravações é registrar de forma fidedigna os dados colhidos, bem como disponibilizá-los para posteriores pesquisas, sejam no nível linguístico ou no nível social, para um estudo da identidade do indivíduo, por exemplo. Sobre esta metodologia, Labov (2008 [1972]) também ressalta que o ideal de uma pesquisa sociolinguística é atestar como realmente as pessoas falam, quando não estão sendo gravadas, o que gera o paradoxo do observador, já que só é possível estudar as falas por meio de gravações. Uma solução para esse paradoxo, segundo o autor, seria deixar os entrevistados o mais à vontade possível, para que seu vernáculo possa despontar.

Este artigo apresenta uma pesquisa sociolinguística variacionista baseada nos princípios labovianos, na qual adotamos o modelo quantitativo, uma vez que opera com números e os dados coletados são analisados estatisticamente (TARALLO, 1986). Os dados do corpus foram coletados de entrevistas feitas em duas regiões não urbanas da Ilha de Florianópolis, sendo quatro delas no Distrito do Ribeirão da Ilha e quatro no Bairro da Costa da Lagoa. Essas entrevistas constituem o Banco Floripa, formado por entrevistas coletadas em duas épocas: em 2011 por alunos da disciplina de Sociolinguística e Dialetologia o Curso de Pós-graduação em Linguística da UFSC e em 2006 por Monguilhott - amostra especialmente coletada para sua tese de doutorado. Ambas as amostras estão arquivadas no banco de dados do Projeto VARSUL (Variedade Linguística na Região Sul do Brasil), da agência UFSC. As entrevistas foram selecionadas de acordo com critérios de estratificação social dos informantes, a saber, homens e mulheres, sendo estes divididos entre mais escolarizados (nível superior) e menos escolarizados (ensino fundamental) e ainda, mais velhos (acima de 45 anos) e mais jovens (abaixo de 45 anos), todos falantes nativos do PB, nativos da Ilha de Santa Catarina, sendo filhos de pais também nativos. Vale ressaltar que, para este trabalho, foram utilizadas oito entrevistas, sendo que o grupo de fatores sexo não foi considerado na categorização dos dados.

Após a seleção das entrevistas, foram feitas audições, nas quais todas as sentenças em que havia a presença de verbos monoargumentais foram selecionadas, totalizando um número de 818 dados. Em seguida, foi feita a categorização dos dados considerando a variável dependente ordem do sujeito (SV sujeito-verbo ou VS verbo-sujeito), a qual foi correlacionada a fatores internos ou linguísticos - tipo de verbo (inergativo, inacusativo existencial e inacusativo não existencial); forma de realização do sujeito (sintagma nominal 
ou pronome); animacidade do sujeito (mais animado ou menos animado); concordância entre sujeito e verbo (concordância ou não concordância) - e a fatores externos ou extralinguísticos - escolaridade (mais escolarizado ou menos escolarizado) e idade (mais velho ou mais jovem).

Para o processo de análise, todos os dados foram rodados no programa Goldvarb (2001) para Windows. Esse programa consiste em um aplicativo que foi desenvolvido especialmente para análise sociolinguística variacionista. Com as análises feitas através do programa, foi possível fazer uma análise quantitativa multivariável. Interpretamos os dados numéricos apresentados pelo programa e apresentamos gráficos e tabelas que representam o percentual de ocorrência das variáveis dadas pelas análises binárias e pelos pesos relativos, resultantes da análise multidimensional. Dessa forma, observamos quais grupos foram selecionados como mais significativos e quais os condicionadores das variantes investigadas: ordens SV e VS nos dados analisados.

Com base em nosso envelope de variação, nos perguntamos como irá se comportar nosso objeto de estudo: a ordem do sujeito em sentenças declarativas com verbos monoargumentais no PB é condicionada somente por fatores internos, ou também por fatores externos? Muitos estudos têm evidenciado que a questão da ordem do sujeito em construções monoargumentais pouco está relacionada a fatores externos ou sociais. Por conta disso, nossa expectativa é de que os fatores internos ou linguísticos sejam mais relevantes na configuração da ordem VS e SV. Mesmo assim condicionadores extralinguísticos também serão controlados.

\section{a. Questões}

(i) O tipo de verbo - inacusativo ou inergativo - é um condicionador que atua na escolha da ordem SV ou VS em construções monoargumentais?

(ii) A forma de realização do sujeito - SN sintagma nominal ou pronome - é um grupo de fatores relevante para diagnosticar a ordem SV ou VS em sentenças, formadas com verbos monoargumentais?

(iii) A animacidade do sujeito - [+ animado] ou [-animado] - é um traço semântico que favorece a ordem SV ou VS em sentenças com verbos monoargumentais?

(iv) A marcação verbal de concordância é mais frequente e provável em construções de ordem SV ou VS?

(v) A escolaridade do informante é um fator que condiciona a escolha da ordem SV ou VS em construções monoargumentais?

(vi) A idade do informante é um fator que condiciona a escolha da ordem SV ou VS em construções monoargumentais?

\section{b. Hipóteses}

(i) Acreditamos que, quanto à ordem do sujeito, verbos inacusativos tendem a formar preferencialmente construções do tipo VS, ou seja, de posposição do sujeito, ao passo que verbos inergativos tendem a aparecer mais frequentemente na ordem SV, ou seja, com sujeito anteposto;

(ii) Quanto à forma de realização do sujeito, nossa expectativa é de que os pronomes apareçam mais na ordem SV e os sujeitos de SN mais na ordem VS;

(iii) Esperamos que, enquanto a ordem $\mathrm{SV}$ tenda a preferir sujeitos com traço [+animado], a ordem VS favoreça sujeito [-animado], em construções de verbos com apenas um argumento; 
(iv) Nossa expectativa é de que construções monoargumentais de ordem SV apresentem maior índice de concordância verbal, uma vez que o sujeito está anteposto ao verbo, ao passo que construções do tipo VS apresentem menores índices de concordância, justamente por se tratarem de construções com o sujeito posposto a verbo;

(v) Acreditamos que, quanto maior a escolaridade do informante, maior o uso de posposição do sujeito - ordem VS - e, consequentemente, quanto menor a escolaridade do informante, maior a probabilidade de aparecimento da ordem SV, direta;

(vi) Esperamos que, quanto maior a idade do informante, maior o uso de posposição do sujeito - ordem VS - e, ao contrário, quanto menor a idade do informante, maior a frequência de uso da ordem SV.

\section{DESCRIÇÃO E ANÁLISE DOS RESULTADOS}

Os resultados gerais de nossa pesquisa podem ser visualizados por meio das Tabelas 1 e 2, que seguem, as quais mostram, respectivamente, a relevância dos grupos de fatores internos e externos controlados:

Tabela 1: Valores em quantidade de dados, percentual e peso relativo para cada um dos grupos de fatores internos controlados em construções com verbos monoargumentais para as ordens SV e VS.

\begin{tabular}{|c|c|c|c|c|c|c|}
\hline $\begin{array}{ll}\text { GRUPO } & \text { DE } \\
\text { FATORES } & \\
\text { INTERNOS } & \end{array}$ & Categorias & $\begin{array}{l}\text { Ordem } \\
\text { SV }\end{array}$ & $\%$ & $\begin{array}{l}\text { Ordem } \\
\text { VS }\end{array}$ & $\%$ & PR \\
\hline Tipo de verbo & $\begin{array}{l}\text { Inergativo } \\
\text { Inacusativo existencial } \\
\text { Inacusativo não } \\
\text { existencial }\end{array}$ & $\begin{array}{l}319 / 344 \\
18 / 227 \\
187 / 247\end{array}$ & $\begin{array}{l}93 \% \\
7 \% \\
75 \%\end{array}$ & $\begin{array}{l}25 / 344 \\
209 / 227 \\
60 / 247\end{array}$ & $\begin{array}{l}7 \% \\
93 \% \\
25 \%\end{array}$ & $\begin{array}{l}0,19 \\
0,92 \\
0,39\end{array}$ \\
\hline $\begin{array}{l}\text { Forma de realização do } \\
\text { sujeito }\end{array}$ & $\begin{array}{l}\text { Sintagma nominal (SN) } \\
\text { Pronome }\end{array}$ & $\begin{array}{l}176 / 453 \\
348 / 365\end{array}$ & $\begin{array}{l}38 \% \\
95 \%\end{array}$ & $\begin{array}{l}277 / 453 \\
17 / 365\end{array}$ & $\begin{array}{l}62 \% \\
5 \%\end{array}$ & $\begin{array}{l}0.73 \\
0,21\end{array}$ \\
\hline Animacidade do sujeito & $\begin{array}{l}\text { [+animado] } \\
\text { [-animado] }\end{array}$ & $\begin{array}{l}480 / 587 \\
44 / 231\end{array}$ & $\begin{array}{l}82 \% \\
20 \%\end{array}$ & $\begin{array}{l}107 / 587 \\
187 / 231\end{array}$ & $\begin{array}{l}18 \% \\
80 \%\end{array}$ & $\begin{array}{l}0,45 \\
0,62\end{array}$ \\
\hline Concordância & $\begin{array}{l}\text { Concorda } \\
\text { Não concorda }\end{array}$ & $\begin{array}{l}476 / 751 \\
48 / 67\end{array}$ & $72 \%$ & $\begin{array}{l}275 / 751 \\
19 / 67\end{array}$ & $28 \%$ & $\begin{array}{l}0,50 \\
0,41\end{array}$ \\
\hline
\end{tabular}


Tabela 2: Valores em quantidade de dados, percentual e peso relativo para cada um dos grupos de fatores externos controlados em construções com verbos monoargumentais para as ordens SV e VS.

\begin{tabular}{|l|l|ll|ll|l|}
\hline $\begin{array}{l}\text { GRUPOS } \\
\text { FATORES } \\
\text { EXTERNOS }\end{array}$ & Categorias & $\begin{array}{l}\text { Ordem } \\
\text { SV }\end{array}$ & $\%$ & $\begin{array}{l}\text { Ordem } \\
\text { VS }\end{array}$ & $\%$ & PR \\
\hline Escolaridade & Fundamental & $304 / 485$ & $65 \%$ & $181 / 485$ & $37 \%$ & 0,56 \\
& Superior & $220 / 333$ & $67 \%$ & $113 / 333$ & $33 \%$ & 0,40 \\
& Idade & $249 / 378$ & $65 \%$ & $129 / 378$ & $35 \%$ & 0,48 \\
& Jovem & $275 / 440$ & $63 \%$ & $165 / 440$ & $37 \%$ & 0,51 \\
\hline
\end{tabular}

De acordo com o programa Goldvarb (2001), e também com base na Tabela 1, referente aos grupos de fatores linguísticos controlados, a variável independente tipo de verbo é a mais relevante para explicar a ordem do sujeito em sentenças com verbos monoargumentais. Conforme se pode observar, verbos inergativos preferem a ordem SV, isto é, o sujeito anteposto ao verbo, ao passo que, na ordem VS há predominância de construções com verbos inacusativos, em especial com inacusativos existenciais, o qual apresentou peso relativo de 0,92 para o tipo verbal, resultado que atesta nossa hipótese e corrobora resultados dos trabalhos citados em nossa pesquisa. $\mathrm{O}$ segundo fator interno selecionado foi a forma de realização do sujeito, com um peso relativo de 0,73 para sintagmas nominais, contra 0,21 para pronomes. Como pode ser observado na Tabela 1, a ordem SV é construída, na maioria dos casos, com pronomes, com 95\% dos casos, enquanto a ordem VS é construída preferencialmente com sintagmas nominais, atestando nossa hipótese.

O terceiro grupo de fatores interno selecionado foi animacidade do sujeito. Como apontamos, nossa hipótese era de que a ordem SV selecionaria sujeitos com traço [+animado], justamente por ser um tipo de construção que se dá por meio de um sujeito agentivo, uma característica de verbos inergativos. Por outro lado, apontamos que a ordem VS selecionaria tanto sujeitos com traço [+animado] como sujeitos com traço [-animado]. Os resultados da Tabela 1 confirmaram nossas expectativas: apenas 18\% (107 de 587 dados) dos dados relacionados à ordem SV são sujeitos com traço [-animado]; já na ordem VS, como esperávamos, $80 \%$ dos dados (187 de 231 dados) são provenientes de sujeitos inanimados. $\mathrm{O}$ Gráfico 1, a seguir, mostra a relação entre os grupos de fatores tipo de verbo e animacidade do sujeito: 
Gráfico 1: Valores em quantidade de dados para o cruzamento entre as variáveis independentes tipo de verbo e animacidade do sujeito.

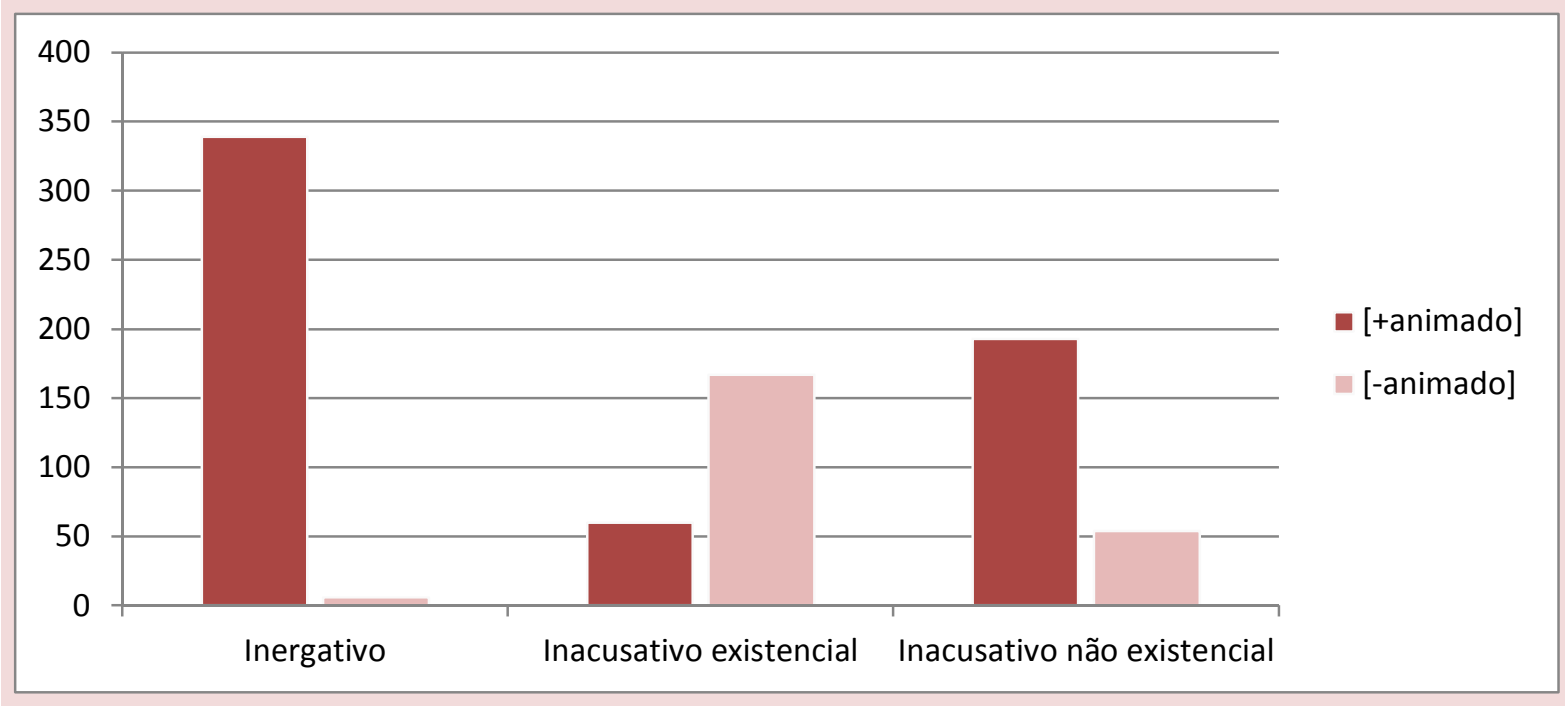

De acordo com o Gráfico 1, pode-se atestar que, de fato, verbos inergativos selecionam sujeitos agentivos, visto que apenas 6 das 344 sentenças construídas com esse tipo verbal são formadas com sujeitos com traço [-animado], o que equivale a $2 \%$ dos dados, confirmando o diagnóstico apresentado por Ciríaco e Cançado (2004) e os resultados de Coelho et al. (2006). É importante ressaltar que esses $2 \%$ correspondem a construções metonímicas como, por exemplo, "a comunidade tá crescendo" e "todo dia a Van vem buscar a gente", dados reais de fala extraídos da nossa análise.

O último grupo de fatores interno controlado, concordância, embora não tenha sido selecionado pelo programa Goldvarb (2001), mostrou-se relevante em nossa pesquisa, uma vez que, de acordo com a Tabela 1, para as 751 sentenças com concordância, 64\% (476 de 751 dados) das construções SV apresentaram marca de concordância entre sujeito e verbo, enquanto apenas 36\% (275 de 751 dados) das construções VS concordaram, resultado que corrobora o estudo de Monguilhot (2001) e que atesta nossa hipótese, já que esperávamos um maior índice de concordância para construções em que o sujeito aparece anteposto ao verbo.

Quanto aos grupos de fatores externos controlados - escolaridade e idade -, apresentados na Tabela 2, é possível verificar que não são relevantes para diagnosticar a inacusatividade no $\mathrm{PB}$, tampouco para determinar a ordem do sujeito em sentenças com verbos monoargumentais. O que se observa é um equilíbrio nos resultados para ambas as construções - SV e VS - para os dois grupos. Tal equilíbrio não atestou nossas hipóteses, pois esperávamos que informantes com maior escolaridade e com maior idade usassem com mais frequência a ordem VS, o que não ocorreu.

Enfim, este trabalho apenas vem confirmar que a ordem do sujeito parece estar correlacionada principalmente a grupos de fatores linguísticos, tais como tipo de verbo, forma de realização do sujeito, animacidade do sujeito e concordância. A ordem SV é construída preferencialmente com verbos inergativos, com marca de concordância e com sujeitos pronominais agentivos, isto é, com traço [+animado], ao passo que a ordem VS constitui-se preferencialmente de verbos inacusativos existenciais, sem marca de concordância, sendo formada por sujeitos do tipo sintagma nominal, que tanto podem ser agente ou tema, aceitando traços [ \pm animados]. 


\section{CONSIDERAÇÕES FINAIS}

Sabe-se que os falantes não têm percepção consciente quanto às regras gramaticais profundas (regras abstratas da fonologia e da sintaxe) de sua língua, o que nos leva a pensar que fatores externos pouco (ou nada) influenciam a variação na sintaxe. Diz Labov (2008 [1972], p. 315) que, embora se observe que os fatores sociais alteram de maneira intensa a fonética e o vocabulário de uma língua e algumas de suas formações superficiais, ainda assim seria possível alegar que "a mudança linguística em regras de nível mais alto é um mero reajuste interno", ou seja, que ela pode se dar, em determinados casos, sem influência externa. Além disso, Labov (2008 [1972]) assegura que as regras variáveis, quando não estão associadas a valores sociais, não são comumente percebidas pelos falantes, mas, ao contrário, quando possuem estigma dentro da sociedade, são facilmente notadas.

Já no texto pioneiro de 1968, Weinreich, Labov e Herzog (2006 [1968]) asseguravam que os resultados de uma mudança, por exemplo, podem estar pouco correlacionados a fatores sociais, como seria o caso do fenômeno sobre a monotongação do ditongo decrescente $/ o w />$ $o-$, já que ocorre em todas as regiões do Brasil, atingindo todas as faixas etárias, sem demarcar diferentes grupos socioeconômicos. Acreditamos que o mesmo deve ocorrer com o nosso objeto de estudo, visto que a ordem do sujeito no PB parece ser determinada apenas por grupos de fatores linguísticos. É importante ressaltar também que muitos desses resultados, determinados basicamente por variáveis linguísticas, são possíveis quando os contextos em variação não se tratam de variantes de uma mesma variável.

\section{REFERÊNCIAS}

BARBOZA, J. S. Grammatica philosophica da lingua portugueza. $2^{\mathrm{a}}$ ed. Lisboa: Typographia da Academia Real das Sciencias, 1830.

BERLINCK, R. de A. A construção V SN no Português do Brasil: uma visão diacrônica do fenômeno da ordem. In: TARALLO, F. (Org.) Fotografias sociolingüísticas. Campinas, Pontes, 1989.

CALVET, L. J. Sociolinguística: uma introdução crítica. Tradução de Marcos Marcionilo. São Paulo: Parábola, 2002 [1993]. 174 p.

CIRÍACO, L.; CANÇADO, M. Inacusatividade e inergatividade do PB. Caderno de Estudos Linguísticos 46(2) Jul./Dez. 2004, UFMG, Campinas (SP), p. 207-225, 2004.

COELHO, I. L. Sobre a natureza do verbo monoargumental na ordem V NP. II Congresso Nacional da ABRALIN. Florianópolis, UFSC, no período de 25 a 27 de fev., p. 75-93, 1999.

A ordem V SN em construções monoargumentais: uma restrição sintático-semântica. Florianópolis: UFSC, 2000. Tese de doutorado.

COElHO, I. L.; MONGUILHOTT, I.; MARTINS, M. A.; COSTA, S.; MAFRA, G. O estatuto das construções monoargumentais no $\mathrm{PB}$ : por trás das frequências. In: VANDRESEN, P. (Org.). Variação, Mudança e Contato Lingüístico no Português da Região Sul. Pelotas: EDUCAT, 2006, v., p. 205-225.

COELHO, I. L.; GÖRSKI, E.; MAY, G.; NUNES DE SOUZA, C. M. Sociolinguística. Florianópolis: LLV/CCE/UFSC, 2010. 172 p.

FREITAG, R. M. K, MITTMANN, M. M. Goldvarb 2001 Comandos e recursos da ferramenta computacional na análise de regras variáveis. $5^{\mathrm{a}}$ Semana de Ensino, Pesquisa e Extensão da UFSC, 16 de setembro de 2005. 
GUY, G. As comunidades de fala: fronteiras internas e externas. In: Anais do II Congresso Internacional da ABRALIN, Fortaleza, marco de 2001.

LABOV, W. Padrões sociolinguísticos. Tradução de Marcos Bagno, Maria Marta Pereira Scherre, Caroline R. Cardoso. Rio de Janeiro: Parábola, 2008 [1972], p. 215-373.

MONGUILHOTT, I. de O. e S. Variação na concordância verbal de terceira pessoa do plural na fala dos florianopolitanos. Florianópolis: 2001, UFSC. Dissertação de Mestrado.

PONTES, E. O tópico no português do Brasil. Campinas: Pontes Editores, 1987.

TARALLO, F. A Pesquisa Sociolingüística. 2 ed. São Paulo: Editora Ática, 1986.

WEINREICH, U.; LABOV, W.; HERZOG, M. I. Fundamentos empíricos para uma teoria da mudança linguística. Tradução de Marcos Bagno. São Paulo: Parábola Editorial, 2006 [1968], p. 87-126.

ZILLES, A. M. S. A posposição do Sujeito ao Verbo no Português Falado no Rio Grande do Sul. Letras de Hoje. Porto Alegre. V. 35, nº 1, p. 75 - 96, março de 2000.

Data de submissão: 12/06/2013

Data de aceite: 16/10/2013 